\section{RMD Open}

Rheumatic \&

Musculoskeletal Diseases

\title{
Association between number and type of different ACPA fine specificities with lung abnormalities in early, untreated rheumatoid arthritis
}

Vijay Joshua (D), ${ }^{1}$ Aase Haj Hensvold,${ }^{1}$ Gudrun Reynisdottir, ${ }^{1}$ Monica Hansson, ${ }^{1}$ Martin Cornillet, ${ }^{2}$ Leonor Nogueira, ${ }^{2}$ Guy Serre, ${ }^{2}$ Sven Nyren, ${ }^{3}$ Reza Karimi, ${ }^{4}$ Anders Eklund, ${ }^{4}$ Magnus Sköld, ${ }^{4}$ Johan Grunewald, ${ }^{4}$ Katerina Chatzidionysiou (D), ${ }^{1}$ Anca Catrina ${ }^{1}$

To cite: Joshua V, Hensvold AH, Reynisdottir G, et al. Association between number and type of different ACPA fine specificities with lung abnormalities in early, untreated rheumatoid arthritis. RMD Open 2020;6:e001278. doi:10.1136/rmdopen-2020001278

- Supplemental material is published online only. To view please visit the journal online (http://dx.doi.org/10.1136/rmdo pen-2020-001278).

$\mathrm{KC}$ and $\mathrm{AC}$ contributed equally to this work.

Received 17 April 2020

Revised 16 June 2020

Accepted 21 August 2020
Check for updates

(C) Author(s) (or their employer(s)) 2020. Re-use permitted under CC BY-NC. No commercial re-use. See rights and permissions. Published by BMJ.

For numbered affiliations see end of article.

Correspondence to

Anca Catrina;

anca.catrina@ki.se

\section{ABSTRACT}

Background Rheumatoid arthritis (RA)-associated anticitrullinated protein/peptide antibodies (ACPA) might originate at mucosal sites such as the lungs. We aimed to examine the relationship between the ACPA repertoire and lung abnormalities on high-resolution CT (HRCT) in patients with earlyuntreated RA.

Methods 106 patients with newly diagnosed untreated RA were examined with HRCT of the lungs. Blood samples were analysed for presence of rheumatoid factor (RF) and ACPA using either a CCP2 detection kit or an immunochip containing 10 different citrullinated peptides. Association between HRCT findings and the antibody repertoire was assessed by logistic regression analysis.

Results The number (\%) of patients with HRCT abnormalities was $58(54.7 \%)$ for parenchymal abnormalities and 68 (64.2\%) for airway abnormalities. CCP2 IgG, RF IgA and antibodies against citrullinated fibrinogen were associated with the presence of parenchymal lung abnormalities. Interestingly, a high number of ACPA fine specificities gave a high risk of having parenchymal lung abnormalities at the time of RA diagnosis. No significant signals were identified between ACPA specificities and risk for airway abnormalities.

Conclusions The presence of RF and ACPAs (especially against citrullinated fibrinogen peptides) as well as high number of ACPAs fine specificities are associated with parenchymal lung abnormalities in patients with early, untreated RA. This provides further support for an important pathogenic link between the lung and systemic autoimmunity, contributing to RA development.

\section{BACKGROUND}

Rheumatoid arthritis (RA) is a chronic inflammatory disease of autoimmune aetiology. Anticitrullinated protein/peptide antibodies (ACPA) and rheumatoid factor (RF) are associated with RA and develop in a majority of patients, years prior to the onset of the disease. ${ }^{12}$ RFs are autoantibodies that recognise the Fc portion of IgG, whereas ACPA

\section{Key messages}

What is already known about this subject?

- HRCT abnormalities are present in the lungs of seropositive individuals at risk of developing RA and early untreated seropositive RA.

What does this study add?

- This study shows that specific ACPA and RF isotypes associate with the presence of parenchymal lung abnormalities (as assessed by HRCT) already at the disease onset and before any treatment initiation in RA patients.

- Also, presence of multiple ACPA reactivities and specifically reactivity against citrullinated fibrinogen significantly increased the risk of detecting HRCT parenchymal abnormalities.

How might this impact on clinical practice?

- The current findings give further support for an important pathogenic link between the lungs and the joints in early seropositive RA and might contribute in the future to a change in the clinical monitoring of the patients at high risk for presence of lung abnormalities.

recognise epitopes containing the noncoding amino acid citrulline, formed by arginine deimination in the presence of peptidylarginine deiminase enzymes. Several such epitopes recognised by ACPA have been identified $^{3}$ and robust methods to simultaneously detect multiple reactivity against these epitopes in one single serum sample has recently been developed. ${ }^{4}{ }^{5}$ Using these methods, it has been shown that the ACPA repertoire is undergoing epitope spreading with increased number of citrullinated epitopes being recognised closer to disease onset. $^{5-7}$ 
The presence of ACPA in the serum long before clinical signs of inflammation in the joint has led to the hypothesis that ACPA and possibly RF production might occur at sites other than the joints. Mucosal surfaces, particularly the lungs, have been suggested as one possible site for triggering of an immune response and initiation of RA, ${ }^{8}$ based on the epidemiological association between smoking and ACPA/RF-positive RA. ${ }^{9}{ }^{10}$ In agreement with this hypothesis, increased citrullination of proteins is present in the lungs of both healthy smokers ${ }^{11}$ and early, untreated ACPA-positive RA. ${ }^{12}$ Further, ACPA are enriched in bronchoalveolar lavage fluid of early, untreated ACPA-positive RA and in the sputum of ACPA individuals at risk for developing RA. ${ }^{12}{ }^{13}$ Lung abnormalities detected by high-resolution CT (HRCT) are more prevalent in ACPA-positive individuals at risk for developing RA as compared to healthy (not at risk) matched controls. ${ }^{14}$ Similarly, both airway and parenchymal HRCT abnormalities are more frequent among patients with early, untreated RA compared to healthy controls ( $54 \%$ vs $30 \%$ for parenchymal abnormalities and $66 \%$ vs $42 \%$ for airway abnormalities). ${ }^{12}$ Accumulation of immune cells (macrophages, T cells) and upregulation of inflammatory markers are present in the lungs of patients with early RA as compared to healthy individuals. ${ }^{15}$ This along with the identification of germinal centre-like structures ${ }^{16}$ further support the notion that local immune activation and ACPA production can occur in the lungs of RA. Presence of shared citrullinated epitopes in the lungs and joints of $\mathrm{RA}^{17}$ might partially explain how immune cells primed in the lungs will elicit their effector functions in the joints.

To get further insights into the role of the lung compartment in autoimmunity initiation in RA, we analysed the ACPA and RF repertoire in a unique cohort of patients with early, untreated RA where extensive lung examination, including lung HRCT, is available.

\section{MATERIALS AND METHODS \\ Patients}

One hundred and six consecutive patients with recentonset RA, diagnosed by an experienced rheumatologist at the early arthritis clinic at Karolinska University Hospital, Stockholm, Sweden, and fulfilling the American Rheumatism Association 1987 classification criteria ${ }^{18}$ with patient-reported symptom duration less than 1 year, naive to treatment with oral glucocorticoids and diseasemodifying antirheumatic drugs (DMARDs) were invited to participate in a study investigating lung involvement in RA (LURA study). ${ }^{12}$ Pregnancy and alcohol and/or drug abuse were exclusion criteria. Disease Activity Score in 28 joints (DAS28) using the erythrocyte sedimentation rate, ${ }^{19}$ smoking history, presence of respiratory symptoms (dyspnoea and cough) during the last 12 months before inclusion and self-reported history of pulmonary disease were assessed at inclusion. None of the patients were diagnosed with clinical interstitial lung disease (ILD) with the exception of one patient who had a concomitant diagnosis of chronic obstructive pulmonary disease. There were 11 patients with self-reported asthma, 8 patients who had been treated with inhaled glucocorticoids and 2 patients who had been treated with theophylline. Pulmonary symptoms were present in a small number of patients; dyspnoea was reported by $12 \%$ of patients with RA while cough was present in only $1 \%$ of patients, during the last 12 months before inclusion in the study. ${ }^{12}$ Bone erosions were assessed based on standard radiographs of hands and feet according to clinical routine and were quantified dichotomously based on the presence or absence of at least one bone erosion. Table 1 summarises the characteristics of the patients at inclusion.

\section{High-resolution CT}

HRCT was performed in patients with RA within 1 week after diagnosis using a Siemens Sensation CT instrument at full inspiration using the following parameters: collimator $(0.625 \mathrm{~mm})$, rotation time $0.5 \mathrm{~s}$, pitch $1120 \mathrm{kV}$ and dose modulation (in all patients). Contiguous axial images $(2 \mathrm{~mm})$ were reconstructed with a highfrequency filter of either B60f or B70f.

All images were reviewed for abnormalities, independently with patient identity masked and in random order, by an experienced thoracic radiologist and a pulmonologist, in accordance with the criteria included in the International Classification of HRCT for Occupational and Environmental Respiratory Diseases. ${ }^{20}$ After independent evaluations, consensus on discrepant findings was reached with evaluations still performed in a blinded manner. The HRCT findings were categorised as parenchymal and airway abnormalities based on the embryonic lung development as previously described. ${ }^{21}$ The parenchymal abnormalities included nodules larger than $3 \mathrm{~mm}$, ground-glass opacities, opacities, fibrosis and emphysema. The airway abnormalities included bronchiectasis, air trapping and airway wall thickening.

\section{Spirometry}

Spirometry was performed 1 week after diagnosis. The forced expiratory volume in $1 \mathrm{~s}\left(\mathrm{FEV}_{1}\right)$, vital capacity (VC) and forced vital capacity (FVC) were measured using a spirometer (Vmax 229-6200; Legacy). The diffusing capacity for carbon monoxide (DLco) was measured using the single-breath method and corrected for haemoglobin. Lung function values are expressed as the percentage of predicted, in accordance with the European Community for Steel and Coal standards. ${ }^{22}$ Normal $\mathrm{FEV}_{1}, \mathrm{VC}, \mathrm{FVC}$ and $\mathrm{DL}_{\mathrm{CO}}$ were defined as $>80 \%$ of predicted.

\section{Antibody detection}

Serum from patients was analysed for IgG and IgA antiCCP2 (second-generation) and IgM and IgA RF using the fluoroenzyme immunoassay EliA (Phadia, Uppsala, 
Table 1 Demographic characteristic of patients with early RA (symptom duration less than 1 year) included in the study

\begin{tabular}{|c|c|c|c|c|c|c|c|}
\hline \multirow{2}{*}{$\begin{array}{l}\text { Demographics and } \\
\text { disease characteristics }\end{array}$} & \multirow[b]{2}{*}{ All patients } & \multicolumn{3}{|c|}{ HRCT airway abnormalities } & \multicolumn{3}{|c|}{ HRCT parenchymal abnormalities } \\
\hline & & No & Yes & $P$ value & No & Yes & $P$ value \\
\hline Number & 106 & 38 & 68 & & 48 & 58 & \\
\hline Age, (mean years $\pm S D$ ) & $57.5 \pm 14.1$ & $52.9 \pm 16.0$ & $60.0 \pm 12.3$ & 0.02 & $53.2 \pm 15.6$ & $61.0 \pm 11.7$ & 0.005 \\
\hline Women (n (\%)) & $73(68.9)$ & $23(60.5)$ & 50 (73.5) & 0.17 & $36(75.0)$ & $37(63.8)$ & 0.22 \\
\hline Ever smokers (n (\%)) & $77(72.6)$ & $30(78.9)$ & $47(69.1)$ & 0.28 & $30(62.5)$ & $47(81.0)$ & 0.03 \\
\hline Current smokers (n (\%)) & $31(29.2)$ & $12(31.6)$ & $19(27.9)$ & 0.69 & $11(22.9)$ & $20(34.5)$ & 0.19 \\
\hline Pack-years (median (IQR)) & $\begin{array}{l}11.5 \\
(0-24.1)\end{array}$ & $9.1(0.6-23.1)$ & $\begin{array}{l}13.0 \\
(0-24.1)\end{array}$ & 0.74 & $3.0(0-16.5)$ & $\begin{array}{l}17.3 \\
(4.0-35.5)\end{array}$ & 0.0005 \\
\hline $\begin{array}{l}\text { Anti-CCP2 lgG-positive } \\
(\mathrm{n}(\%))\end{array}$ & $71(67.0)$ & $25(65.8)$ & $46(67.6)$ & 0.85 & $26(54.2)$ & $45(77.6)$ & 0.01 \\
\hline RF-positive (n (\%)) & $73(68.9)$ & $25(65.8)$ & $48(70.6)$ & 0.61 & $29(60.4)$ & $44(75.9)$ & 0.09 \\
\hline $\begin{array}{l}\text { ACPA and RF-negative } \\
(\mathrm{n}(\%))\end{array}$ & $26(24.5)$ & $10(26.3)$ & $16(23.5)$ & 0.75 & $16(33.3)$ & $10(17.2)$ & 0.06 \\
\hline Any HLA-DR SE (n (\%)) & 73 (68.9) & $24(63.2)$ & $49(72.1)$ & 0.34 & $32(66.7)$ & $41(70.7)$ & 0.66 \\
\hline Bone erosions (n (\%)) & $23(21.7)$ & $10(26.3)$ & $13(19.1)$ & 0.39 & $10(20.8)$ & $13(22.4)$ & 0.84 \\
\hline \multicolumn{8}{|l|}{ Disease activity } \\
\hline DAS28 (mean \pm SD) & $5.5 \pm 1.1$ & $5.3 \pm 0.9$ & $5.6 \pm 1.2$ & 0.19 & $5.5 \pm 1.0$ & $5.5 \pm 1.2$ & 0.96 \\
\hline SJC (median (IQR)) & $9(6-13)$ & $9.5(6-12.25)$ & $9(6-13.75)$ & 0.72 & $9.5(7-14)$ & $9(6-13)$ & 0.88 \\
\hline TJC (median (IQR)) & $10(6-13)$ & $9(4-13)$ & $10(6-14)$ & 0.25 & $10(6-13)$ & $\begin{array}{l}9 \\
(4.75-14.25)\end{array}$ & 0.96 \\
\hline CRP (median (IQR)) & $10(4-24)$ & $\begin{array}{l}9.5 \\
(3.5-18.25)\end{array}$ & $\begin{array}{l}10 \\
(4.25-26.5)\end{array}$ & 0.28 & $10(4-24)$ & $9.5(4-22.75)$ & 0.72 \\
\hline ESR (median (IQR)) & $27.5(17-46)$ & $26(14.5-42)$ & $28(18-52)$ & 0.10 & $\begin{array}{l}24.5 \\
(15.25-43.25)\end{array}$ & $\begin{array}{l}32 \\
(18.75-48)\end{array}$ & 0.55 \\
\hline \multicolumn{8}{|c|}{ Pulmonary function test (median (IQR)) } \\
\hline VC (\% of predicted) & $\begin{array}{l}107 \\
(95-119)\end{array}$ & $\begin{array}{l}112 \\
(100-122.5)\end{array}$ & $\begin{array}{l}105 \\
(92.25-115)\end{array}$ & 0.11 & $\begin{array}{l}108 \\
(101.25-119)\end{array}$ & $106(93-120)$ & 0.29 \\
\hline FVC (\% of predicted) & $\begin{array}{l}108 \\
(95.5-117)\end{array}$ & $\begin{array}{l}112 \\
(103.5-125.5)\end{array}$ & $\begin{array}{l}105 \\
(91-114)\end{array}$ & 0.01 & $\begin{array}{l}109.5 \\
(99.75-117.25)\end{array}$ & $105(91-117)$ & 0.17 \\
\hline $\mathrm{FEV}_{1}(\%$ of predicted $)$ & $99(85-110)$ & $\begin{array}{l}100 \\
(89.5-112)\end{array}$ & $\begin{array}{l}95 \\
(81-109.75)\end{array}$ & 0.04 & $\begin{array}{l}103 \\
(90.25-111.25)\end{array}$ & $94(81-104)$ & 0.006 \\
\hline $\mathrm{FEV}_{1} / \mathrm{FVC}$ & $\begin{array}{l}0.76 \\
(0.65-0.80)\end{array}$ & $\begin{array}{l}0.74 \\
(0.65-0.79)\end{array}$ & $\begin{array}{l}0.76 \\
(0.65-0.81)\end{array}$ & 0.46 & $0.77(0.69-0.82)$ & $\begin{array}{l}0.73 \\
(0.63-0.77)\end{array}$ & 0.003 \\
\hline $\mathrm{D}_{\text {LCO }}(\%$ of predicted $)$ & $78(70-88)$ & 77 (66.5-86.5) & $\begin{array}{l}79 \\
(72-89.75)\end{array}$ & 0.74 & $78.5(71-85.25)$ & $78(67-90)$ & 0.82 \\
\hline
\end{tabular}

The data has been further stratified for the presence and absence of HRCT airway and parenchymal abnormalities.

The bolded values represent statistically significant $p$ values $(p<0.05)$.

ACPA, anticitrullinated protein/peptide antibodies; CRP, C reactive protein; DAS28, Disease Activity Score in 28 joints; $D_{\text {Lco, diffusing capacity }}$

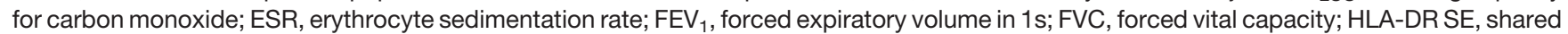
epitope risk allele; HRCT, high-resolution CT; SJC, swollen joint count; TJC, tender joint count; VC, vital capacity.

Sweden) according to the manufacturer's instructions. The cut-off for positivity for all the assays was based on the values provided by the manufacturer. We further assessed ACPA fine specificity against 10 different citrullinated antigens using a custom-made peptide microarray based on the ImmunoCAP ISAC system (Phadia) described previously in detail. ${ }^{4}$ Briefly, glass slides were spotted with the following peptides in their citrullinated and native form: $\alpha$-enolase 5-21 (citrullinated enolase peptide (CEP)-1), filaggrin 307-324 (cyclic citrullinated peptide (CCP)-1), vimentin 2-17 (Vim 2-17), 60-75 (Vim 60-75), fibrinogen- $\alpha$ 36-50 (Fib $\alpha$ 36-50), 563-583 (Fiba 563-583), 580-600 (Fib $\alpha$ 580-600), 621-635 (Fib $\alpha$
621-635) and fibrinogen- $\beta$ 36-52 (Fib $\beta$ 36-52), 60-74 (Fib $\beta$ 60-74). Detailed sequence and position of citrulline amino acids are given in online supplemental table 1. Serum was incubated on the slides and bound autoantibodies were detected using a Cy3conjugated goat antihuman IgG (Jackson ImmunoResearch Laboratories, Newmarket, UK). The fluorescent intensity was measured and converted to arbitrary units $(\mathrm{Au} / \mathrm{mL})$ based on an internal calibrator present in each chip. The cut-off values for positivity were determined as the 98th percentile of the healthy control reactivity using serum obtained from 97 anonymous healthy volunteers. 


\section{HLA-DR genotyping}

The patients with RA were genotyped for the HLA-DRB1 allele as described previously. ${ }^{23}$ HLA-DRB1 *0101, *0102, $* 0401, * 0404, * 0405$ or $* 1001$ alleles were classified as HLA-DR shared epitope alleles. ${ }^{24}$

\section{Statistical analysis}

Comparison of normally and non-normally distributed continuous variables was performed by independent sample Student's t-test and Mann-Whitney U test, respectively. Pearson's $\chi^{2}$ test was used to compare categorical variables. Spearman's rank correlation test was performed for correlation analysis. Smoking status was categorised as ever smokers (which includes both current and former smokers) and current smokers. In the univariate and multivariable regression analysis, age was categorised as above and below 65 years as described previously. ${ }^{12}$ Binomial logistic regression analysis was performed to assess the relationship between the presence of HRCT abnormalities (either parenchymal or airway abnormalities) and a set of predictor variables: age, sex, smoking status (ever vs never), pack-years, presence of bone erosions, DAS28 and presence of autoantibodies (RF IgA, RF IgG, ACPA IgA, ACPA IgG and several ACPA specificities). Age and ever smoking as well as sex were included in the multivariable regression analysis based on the results from univariate analysis and the clinical relevance, respectively. Multivariable regression analysis not including sex did not affect the overall results. Effect modification was tested with the interaction term smoking $\mathrm{x}$ autoantibodies and found to be not significant. Collinearity was assessed by calculating the variance inflation factors $^{25}$ and appropriate test for goodness of fit was performed. The strength of associations was estimated using ORs and 95\% CIs. The level of significance was set to $95 \%$. For multiple testing correction, we used Bonferroni adjustment. Statistical analyses were performed using SPSS version 22.

\section{RESULTS}

\section{HRCT and lung function}

The number (\%) of patients with RA with parenchymal and airway abnormalities on HRCT was 58 (54.7\%) and $68(64.2 \%)$, respectively (table 1$)$. A considerable proportion of patients had both parenchymal and airway lung abnormalities (38.7\%). Baseline demographics as well as data on disease activity and pulmonary function tests are shown in table 1. Patients with lung abnormalities, either parenchymal or airway, were older compared to those without any lung abnormalities. Patients with parenchymal abnormalities were more likely to have smoked and exposed to a high number of pack-years compared to those without any parenchymal lung involvement (table 1). Patients having both airway and parenchymal abnormalities were significantly older and had higher pack-years of smoking compared to those having no or only airway or parenchymal abnormalities. Thirty- six percent of the patients with RA had evidence of air flow limitation, defined as $\mathrm{FEV}_{1} / \mathrm{FVC}<70 \%$ and $52 \%$ had a DLco $<80 \%$ of predicted. FVC was significantly lower in patients with airway abnormalities, while the ratio $\mathrm{FEV}_{1} / \mathrm{FVC}$ was significantly lower in those with parenchymal lung abnormalities (table 1 ). The median ratio $\mathrm{FEV}_{1} / \mathrm{FVC}_{\text {was }}$ within normal range. No associations were observed between self-reported pulmonary complaints and HRCT changes or lung function tests.

\section{Antibody profiles in relation to HRCT findings}

The frequency of the anti-CCP2 antibodies (IgG and $\operatorname{IgA}$ ), RF (IgG and IgA) as well as the different ACPA specificities in the whole cohort and in patients with either parenchymal or airway lung abnormalities are summarised in table 2. Patients with parenchymal lung abnormalities were more often positive for any antiCCP2 and in particular IgG anti-CCP2, as well as RF IgA, compared to patients without parenchymal abnormalities $(\mathrm{p}<0.05$, adjusted $\mathrm{p}=0.25,0.49$ and 0.81 , respectively, table 2). Patients with either parenchymal or airway lung abnormalities had non-significant but numerically higher levels of anti-CCP2 IgG as compared to those without these abnormalities (median (IQR) of 170.0 (18.6$340.0)$ vs 42.0 (1.6-276.0), $\mathrm{p}=0.08$ for parenchymal abnormalities and median (IQR) of 165.0 (2.5-344.0) vs 37.5 (3.3-261.0), $\mathrm{p}=0.08$ for airway abnormalities), while no significant differences were seen for anti-CCP2 IgA (median (IQR) of 6.5 (3.4-18.1) vs 4.5 (2.3-11.4), p=0.2 for parenchymal abnormalities and median (IQR) of 5.8 (2.8-18.1) vs 4.0 (2.6-9.9), p=0.3 for airway abnormalities) (figure $1 \mathrm{~B}$ and $\mathrm{C}$ ). A significant higher percentage of anti-CCP2 IgA positivity $(18 / 41,43.9 \%, \mathrm{p}=0.03)$ was observed among patients having both airway and parenchymal abnormalities compared to the other groups having no or only airway or parenchymal abnormalities. The number of ACPA fine specificities positively correlated with the level of anti-CCP2 (Spearman's correlation $\mathrm{r}=0.84, \mathrm{p}<0.0001$ ) (figure $1 \mathrm{~A}$ ). Interestingly, 13/35 antiCCP2-negative patients tested positive for at least one of the ACPA fine specificities (most frequently 1 ACPA specificity $(n=9)$, followed by $2,(n=3)$ and 1 patient had 4 ACPA fine specificities). Of these 13 individuals, 6 had parenchymal and 8 had airway abnormalities.

RF IgM was detected in $68.9 \%$ of the patients and RF IgA in $49.1 \%$ of the patients. Patients with parenchymal abnormalities had significantly higher levels of RF IgM (median (IQR) of 39 (7.0-159) vs 25 (1.2-71), p=0.038) and RF IgA (median (IQR) of 30.5 (9.6-80.8) vs 11.0 $(6.2-30), \quad \mathrm{p}=0.031)$ compared to patients without abnormalities in parenchyma (figure 1D and E). Similar levels of both RF IgM (median (IQR) of 38.8 (2.2-132.0) vs 40.5 (2.1-76), $\mathrm{p}=0.4$ ) and RF IgA (median (IQR) of $20.0(8.3-51.0)$ vs $14.5(6.5-77.3), \mathrm{p}=0.3)$ were observed in patients with airway abnormalities as compared to those without airway abnormalities, respectively. We found no significant difference between levels of RF IgA 
Table 2 Autoantibody status and association with HRCT lung abnormalities

\section{HRCT airway abnormalities}

HRCT parenchymal abnormalities

\begin{tabular}{|c|c|c|c|c|c|c|c|}
\hline RF and ACPA fine specificities & All patients & No & Yes & $P$ value & No & Yes & $\begin{array}{l}\text { P value } \\
\text { (adjusted } p \text { value) }\end{array}$ \\
\hline Number & 106 & 38 & 68 & & 48 & 58 & \\
\hline Any RF & $73(69.5)$ & $27(71.1)$ & $46(68.7)$ & 0.80 & $29(61.7)$ & 44 (75.9) & 0.12 \\
\hline $\mathrm{RF}(\lg \mathrm{M})$ & $73(69.5)$ & $27(71.1)$ & $46(68.7)$ & 0.80 & $29(61.7)$ & $44(75.9)$ & 0.12 \\
\hline $\operatorname{RF}(\lg A)$ & $52(49.5)$ & $18(47.4)$ & $34(50.7)$ & 0.74 & 17 (36.2) & $35(60.3)$ & $0.014(0.25)$ \\
\hline Any anti-CCP2 & $72(68.6)$ & $25(65.8)$ & $47(70.1)$ & 0.64 & $27(57.4)$ & $45(77.6)$ & $0.027(0.49)$ \\
\hline CCP2 (lgG) & $71(67.6)$ & $25(65.8)$ & $46(68.7)$ & 0.76 & 27 (57.4) & $44(75.9)$ & $0.045(0.81)$ \\
\hline CCP2 $(\lg A)$ & $32(30.5)$ & $9(23.7)$ & $23(34.3)$ & 0.26 & $12(25.5)$ & 20 (34.5) & 0.32 \\
\hline Any RF and anti-CCP2-negative & $24(22.9)$ & $8(21.1)$ & $16(23.9)$ & 0.74 & $16(34.0)$ & $8(13.8)$ & $0.014(0.25)$ \\
\hline Anti-CEP-1 & $41(38.7)$ & $12(31.6)$ & $29(42.6)$ & 0.26 & $18(37.5)$ & $23(39.7)$ & 0.82 \\
\hline Anti-CCP-1 & $48(45.3)$ & $17(44.7)$ & $31(45.6)$ & 0.93 & $19(39.6)$ & $29(50.0)$ & 0.28 \\
\hline Any anti-cit vimentin & $64(61.0)$ & $21(55.3)$ & $43(64.2)$ & 0.37 & $26(55.3)$ & $38(65.5)$ & 0.29 \\
\hline Vim 2-17 & $44(42.7)$ & 14 (38.9) & $30(44.8)$ & 0.57 & 17 (36.2) & $27(48.2)$ & 0.22 \\
\hline Vim $60-75$ & $57(53.8)$ & $17(44.7)$ & $40(58.8)$ & 0.16 & $23(47.9)$ & 34 (58.6) & 0.27 \\
\hline Any anti-cit fibrinogen & 77 (72.6) & $28(73.7)$ & $49(72.1)$ & 0.86 & 30 (62.5) & $47(81.0)$ & $0.033(0.59)$ \\
\hline Fib $\alpha 36-50$ & $28(26.4)$ & 12 (31.6) & $16(23.5)$ & 0.37 & $11(22.9)$ & 17 (29.3) & 0.46 \\
\hline Fib $\alpha$ 563-583 & $50(47.2)$ & $19(50.0)$ & $31(45.6)$ & 0.66 & 19 (39.6) & $31(53.4)$ & 0.16 \\
\hline Fib $\alpha$ 580-600 & 20 (18.9) & $6(15.8)$ & $14(20.6)$ & 0.55 & $9(18.8)$ & $11(19.0)$ & 0.98 \\
\hline Fib $\alpha$ 621-635 & $38(35.8)$ & $11(28.9)$ & $27(39.7)$ & 0.27 & $14(29.2)$ & $24(41.4)$ & 0.19 \\
\hline $\mathrm{Fib} \beta 36-52$ & $48(45.3)$ & $14(36.8)$ & $34(50.0)$ & 0.19 & 19 (39.6) & $29(50.0)$ & 0.28 \\
\hline Fib $\beta$ 60-74 & $57(53.8)$ & $21(55.3)$ & 36 (52.9) & 0.82 & $23(47.9)$ & 34 (58.6) & 0.27 \\
\hline \multicolumn{8}{|l|}{ Number of ACPA fine specificities } \\
\hline 0 & $24(22.6)$ & $9(23.7)$ & $15(22.1)$ & 0.43 & $15(31.3)$ & $9(15.5)$ & 0.12 \\
\hline $1-5$ & $43(40.6)$ & $18(47.4)$ & $25(36.8)$ & & 19 (39.6) & $24(41.4)$ & \\
\hline$>5$ & $39(36.8)$ & $11(28.9)$ & $28(41.2)$ & & $14(29.2)$ & $25(43.1)$ & \\
\hline $0-1$ & 37 (35.2) & $13(35.1)$ & $24(35.3)$ & 0.99 & $19(39.6)$ & $18(31.6)$ & 0.39 \\
\hline$>1$ & $68(64.8)$ & $24(64.9)$ & $44(64.7)$ & & $29(60.4)$ & $39(98.4)$ & \\
\hline
\end{tabular}

The values indicated in the table represent the numbers and those in parenthesis indicate the \% of reactivity (columnwise) in each category. The $p$ values were obtained by $\chi^{2}$ test that was used to compare categorical variables.

The bolded values represent statistically significant $p$ values $(p<0.05)$. The $p$ values in parentheses represent the adjusted values for multiple test (Bonferroni).

ACPA, anticitrullinated protein/peptide antibodies; CCP, cyclic citrullinated peptide; CEP, citrullinated enolase peptide; cit, citrullinated/ citrullination; Fib, fibrinogen; HRCT, high-resolution CT; RF, rheumatoid factor; Vim, vimentin.

and anti-CCP2 IgA when stratified according to the smoking status (figure $1 \mathrm{~F}$ and $\mathrm{G}$ ).

\section{Antibody profiles in relation to spirometry findings}

Comparison of autoantibody status (positive vs negative) between patients with normal versus decreased $\mathrm{FEV}_{1} / \mathrm{FVC}$ and $\mathrm{DL}_{\mathrm{CO}}$ revealed no significant differences (data not shown), but a trend was observed for RF IgA, with more patients having abnormal $\mathrm{FEV}_{1} / \mathrm{FVC}$ testing positive for RF IgA, as compared to those having normal ratio $(54.9 \%$ vs $34.5 \%, \mathrm{p}=0.06)$. In linear regression models with $\mathrm{DL}_{\mathrm{CO}}$ as the dependent variable, no association with any autoantibody was observed (data not shown).

Antibodies patterns predict HRCT parenchymal lung abnormalities

Factors such as age $>65$ years, ever smoking and $>23$ packyears in the univariate logistic regression analysis and factors such as presence of RF IgA, anti-CCP2 IgG and any anti citrullinated (anti-cit) fibrinogen peptide antibody in a univariate analysis were all significantly associated with increased risk for parenchymal lung abnormalities (table 2, online supplemental table 2). The association between antibodies (RF IgM, RF IgA, any anti-CCP2, anti-CCP2 IgG, any anti-cit vimentin antibody, any anti-cit fibrinogen antibody, anti-cit fibrinogen $\alpha$ 563-683, anti-cit fibrinogen $\beta$ 60-74) and parenchymal abnormalities was significant when adjusting for eversmoking, age and sex (table 3, figure 2). Following correction for multiple comparisons, any anti-CCP2, antiCCP2 IgG and any cit-fibrinogen antibody still significantly associated with parenchymal abnormalities. As collinearity analysis showed no association between RF and ACPAs, we performed a logistic regression analysis by including RF in the model which showed that anti-CCP2 

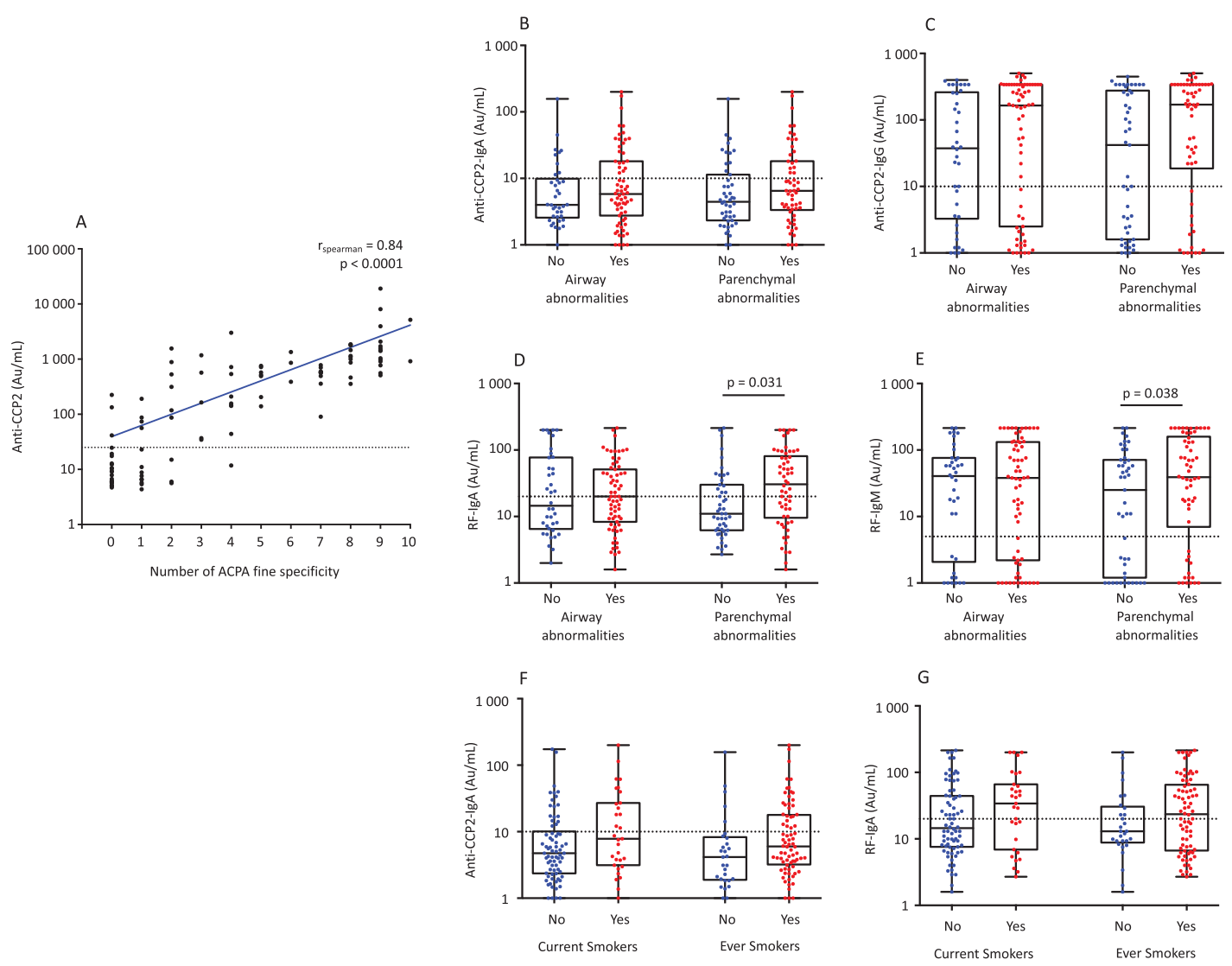

Figure 1 Anti-CCP2 and RF levels and lung abnormalities. (A) The graph represents the correlation between anti-CCP2 levels and the number of ACPA fine specificity. (B, C, D and E) The box plot represents the levels of anti-CCP2 IgA, anti-CCP2 lgG, RF IgA and RF IgM in patients with and without parenchymal lung abnormalities at the time of RA diagnosis. ( $F$ and $G$ ) The box plot represents the levels of anti-CCP2 IgA and RF IgA stratified on smoking status. The dotted line indicates the cut-off for each assay.

ACPA, anticitrullinated protein/peptide antibodies; CCP, cyclic citrullinated peptide; RA, rheumatoid arthritis; RF, rheumatoid factor.

IgG, any anti-cit fibrinogen antibody and the number of different ACPA specificities were significantly associated with parenchymal abnormalities in non-adjusted comparisons but not following adjustment for multiple comparisons (table 3 , figure 2 ). Sensitivity analysis limited to the ACPA-positive patients gave similar results (online supple mental table 3). Similarly, sensitivity analysis performed by excluding emphysema from parenchymal abnormalities and including it among the airway abnormalities did not alter the observations (data not shown).

Number of ACPA specificities expressed as either a categorical or a continuous variable significantly associated with presence of parenchymal but not airway abnormalities (online supplemental table 4, figure 2). No significant association was found between the ACPA fine specificities and individual subcomponents of the HRCT parenchymal abnormalities (online supplemental table 5).

\section{DISCUSSION}

Mucosal immune activation with antibody generation has been proposed as an initiating event in ACPA-positive RA.
We show here that specific ACPA and RF isotypes associate with the presence of parenchymal lung abnormalities (as assessed by HRCT) already at the disease onset and before any treatment initiation in patients with RA. Presence of multiple ACPA reactivities and specifically reactivity against citrullinated fibrinogen significantly increased the risk of detecting these abnormalities. Our findings give further support for an important pathogenic link between the lungs and the joints in early ACPA-positive RA.

While lung complications are classically associated with long-standing, uncontrolled and seropositive RA disease ${ }^{26-28}$ less is known about the association between autoimmunity and subclinical lung inflammation in patients with early RA. Notably, patients in our study had a short duration of symptoms (less than 1 year, median 6 months) and were not treated with any antirheumatic treatment (neither DMARDs nor corticosteroids). We have previously reported that anti-CCP2 antibodies associate with presence of HRCT abnormalities in this cohort. Here, we extend on our previous findings and show that only specific isotypes of anti-CCP2 antibodies and also RF associate with lung HRCT abnormalities. 
Table 3 Association between autoantibodies and HRCT parenchymal lung abnormalities

\begin{tabular}{|c|c|c|c|c|}
\hline & \multicolumn{2}{|c|}{ Adjusted for age, sex and ever smoking } & \multicolumn{2}{|c|}{ Adjusted for age, sex, ever smoking and any RF } \\
\hline & OR (95\% Cl) & $\begin{array}{l}\text { P value } \\
\text { (adjusted } p \text { value) }\end{array}$ & OR (95\% Cl) & $\begin{array}{l}\text { P value } \\
\text { (adjusted } p \text { value) }\end{array}$ \\
\hline Any RF & $2.5(1.0-6.2)$ & $0.05(0.9)$ & & \\
\hline $\mathrm{RF}(\lg \mathrm{M})$ & $2.5(1.0-6.2)$ & $0.05(0.9)$ & & \\
\hline$R F(\lg A)$ & $3.1(1.3-7.6)$ & $0.01(0.2)$ & & \\
\hline Any anti-CCP2 & $5.2(1.9-14.7)$ & $0.002(0.04)$ & $5.6(1.5-20.3)$ & $0.01(0.2)$ \\
\hline CCP2 (IgG) & $4.6(1.7-12.4)$ & $0.003(0.05)$ & $4.7(1.3-17.3)$ & $0.02(0.3)$ \\
\hline CCP2 $(\lg A)$ & $1.5(0.6-3.8)$ & 0.37 & $1.1(0.4-3.1)$ & 0.79 \\
\hline CEP-1 & $1.4(0.6-3.2)$ & 0.48 & $1.0(0.4-2.6)$ & 0.93 \\
\hline CCP-1 & $2.1(0.9-5.0)$ & 0.09 & $1.5(0.6-3.9)$ & 0.4 \\
\hline Any anti-cit vimentin & $3.1(1.2-7.9)$ & $0.02(0.4)$ & $2.3(0.8-6.9)$ & 0.13 \\
\hline Vim 2-17 & $2.2(0.9-5.2)$ & 0.09 & $1.6(0.6-4.1)$ & 0.37 \\
\hline Vim 60-75 & $2.7(1.1-6.6)$ & $0.03(0.6)$ & $2.0(0.7-5.4)$ & 0.17 \\
\hline Any anit-cit fibrinogen & $4.9(1.8-13.9)$ & $0.002(0.04)$ & $4.2(1.2-14.7)$ & $0.03(0.5)$ \\
\hline Fib $\alpha 36-50$ & $1.6(0.6-4.2)$ & 0.30 & $1.4(0.5-3.6)$ & 0.54 \\
\hline Fib $\alpha$ 563-583 & $2.8(1.2-6.9)$ & $0.02(0.4)$ & $2.1(0.8-5.7)$ & 0.13 \\
\hline Fib $\alpha 580600$ & $1.2(0.4-3.4)$ & 0.77 & $0.8(0.2-2.4)$ & 0.65 \\
\hline Fib $\alpha$ 621-635 & $1.9(0.8-4.5)$ & 0.16 & $1.4(0.5-3.6)$ & 0.51 \\
\hline $\mathrm{Fib} \beta 3$ 36-52 & $1.9(0.8-4.4)$ & 0.13 & $1.4(0.6-3.5)$ & 0.46 \\
\hline Fib $\beta$ 60-74 & $2.4(1.0-5.7)$ & $0.05(0.9)$ & $1.6(0.5-5.0)$ & 0.45 \\
\hline \multicolumn{5}{|c|}{ Number of ACPA fine specificities } \\
\hline 0 & Reference & & Reference & \\
\hline $1-5$ & $3.8(1.2-12.1)$ & 0.03 & $3.1(0.9-10.9)$ & 0.07 \\
\hline$>5$ & $6.0(1.8-20.1)$ & 0.004 & 4.5 (1.1-18.8) & 0.04 \\
\hline $0-1$ & Reference & & Reference & \\
\hline$>1$ & $2.9(1.1-7.4)$ & 0.03 & $2.0(0.6-6.4)$ & 0.24 \\
\hline $\begin{array}{l}\text { No. of ACPA fine specificities } \\
\text { (as continuous) }\end{array}$ & $1.2(1.0-1.3)$ & 0.04 & $1.09(1.0-1.3)$ & 0.23 \\
\hline
\end{tabular}

The table represents the results from logistic regression analysis. The OR on the left column are adjusted for age, sex and smoking while the right column is adjusted for age, sex, ever smoking and any RF, with HRCT parenchymal lung abnormalities as the outcome variable and several types of autoantibodies and ACPA specificities as independent variables. The bolded values represent a statistically significant $O R(p<0.05)$. The $p$ values in parentheses represent the adjusted values for multiple test (Bonferroni).

ACPA, anticitrullinated protein/peptide antibodies; CCP, cyclic citrullinated peptide; CEP, citrullinated enolase peptide; cit, citrullinated/ citrullination; Fib, fibrinogen; HRCT, high-resolution CT; RF, rheumatoid factor; Vim, Vimentin.

Interestingly, this association is related to the $\operatorname{IgG}$ isotype of anti-CCP2 antibodies and the IgA isotype of RF. One explanation for this difference might rely on the different sensitivity and specificity of each of these isotypes. IgG anti-CCP2 antibodies occur more often and are more specific for the RA diagnosis than IgA anti-CCP2 and it has been suggested that presence of IgA anti-CCP2 might even be an indirect measure of an adaptive protective mechanism at mucosal sites. ${ }^{29-31}$ Similarly, IgA RF has greater sensitivity and positive predictive value for the diagnosis of RA than IgM RF. ${ }^{2}$ As such, it is possible that IgG-CCP2 and IgA-RF, and potentially also the fine ACPA specificities, rather than the more non-specific IgA-CCP2 and IgG-RF, would reflect a disease-associated event such as the early HRCT parenchymal changes. Our findings are in line with a recent study showing association of RF IgA and IgG anti-CCP2 with subclinical HRCT lung abnormalities in community-dwelling adults, where information on IgA anti-CCP2 and concomitant RA was however missing. An important confounder in assessing the correlation between lung HRCT abnormalities and presence of antibodies (especially ACPA) is smoking. It is well established that in healthy individuals smoking associates with both ACPA development ${ }^{17}$ and presence of lung HRCT abnormalities, ${ }^{14}$ introducing therefore a potential statistical problem due to multicollinearity. However, in this study, no significant correlation between ever smoking and autoantibodies was observed and adjustment of the regression analysis for ever smoking and pack-years did not modify the results.

Association of parenchymal but not airway abnormalities with RA-associated antibodies (despite over-representation of both abnormalities among patients with RA as compared to controls, ${ }^{12}$ ) suggest different pathophysiological roles of these abnormalities. We speculate that 


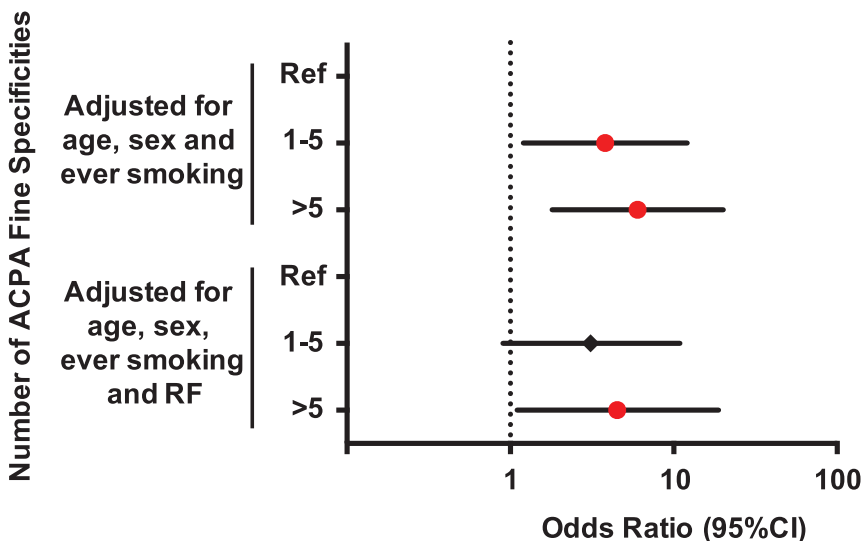

Parenchymal abnormalities

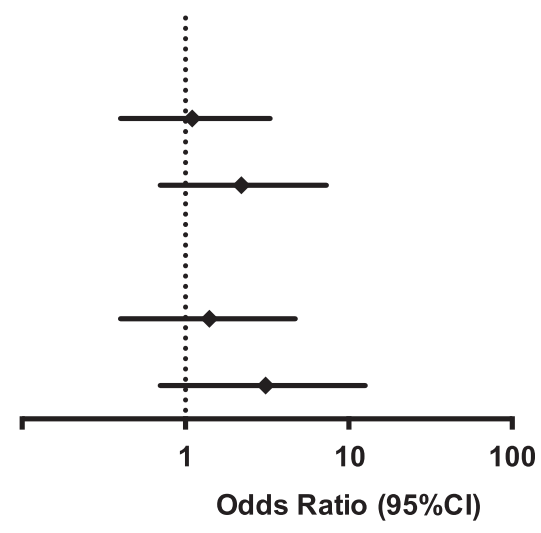

Airway abnormalities

Figure 2 Association between number of ACPA fine specificity and HRCT lung abnormalities. The forest plot represents the OR $(95 \% \mathrm{Cl})$ between the number of ACPA fine specificities (1-5 and $>5)$ and having parenchymal or airway abnormalities. The significant OR ( $p$ value $<0.05$ ) are represented by red circles $(\cdot)$.

ACPA, anticitrullinated protein/peptide antibodies; HRCT, high-resolution CT.

parenchymal changes associated with systemic autoimmunity might be compatible with an antibody-generating immune process in the lungs, while the more general airway changes present in both seropositive and seronegative RA might reflect a more general non-specific inflammation process in the lungs, not related to the antibodypositive variant of the disease. In line with this hypothesis, a previous study demonstrated HRCT patterns indicative of small airway disease to be more prominent in patients with long-standing RA. In contrast, parenchymal abnormalities were frequently observed already in early RA even in the absence of respiratory symptoms. ${ }^{32}$

We find a significant association between presence of anti-cit fibrinogen antibodies and parenchymal abnormalities, as opposite to anti-cit vimentin and anti-cit enolase (CEP-1). The relevance of this finding needs to be further investigated and interpreted with some caution as far as we tested for a larger number of anti-cit fibrinogen specificities $(n=6)$ as compared to both anti-cit vimentin $(n=2)$ and anti-cit enolase specificities $(\mathrm{n}=1)$. We report a significant association between the number of ACPA specificities and the presence of parenchymal lung abnormalities, suggesting that early events in the lung might be linked with epitope spreading, an important early phase in the development of RA-associated autoimmunity and disease. While an association between the number of ACPAs and presence of lung fibrosis has been previously reported in long-standing RA with concomitant ILD, ${ }^{33}$ no other studies have investigated this in the context of early disease and before treatment initiation. Interestingly, while the number of ACPA specificities associates with presence of parenchymal abnormalities (defines as nodules larger than $3 \mathrm{~mm}$, ground-glass opacities, fibrosis and emphysema), we do not see any association with fibrosis, which was uncommon in our patients with early, untreated RA. It is therefore possible that parenchymal subclinical HRCT abnormalities as described here might reflect early autoimmune activation and inflammation in the lungs, ${ }^{12} 14$ while advanced fibrotic lesions as those described by Giles et $a l^{33}$ mainly reflect a secondary injury to the lungs in the context of long-standing seropositive RA where the antibodies might contribute to this damage. However, the exact time relationship between events in the lungs and in the joints still remains a debated issue. Our findings might also have clinical implications, suggesting that active screening for lung abnormalities might be justified in early patients at high risk, such as those with high level of antibodies, high number of ACPA specificities and smokers. However, validation in larger trials and longterm follow-up is needed before these recommendations could be generalised in clinical practice. Main limitations of our study are the relatively low number of patients included and the lack of the long-time follow-up clinical data regarding the progression of the subclinical lung changes observed in this study to clinical RA-related ILD. The latter could add additional information about the pathogenesis of RA-related clinical ILD.

We have previously demonstrated association between the anti-CCP2 IgG and presence of parenchymal lung abnormalities. ${ }^{12}$ Building on this original observation, our main novel findings are (1) presence of some but not all ACPA reactivities associated with lung parenchymal abnormalities in early untreated RA, (2) epitope spreading with recognition of multiple epitopes associated with lung parenchymal abnormalities in early, untreated RA and (3) some but not all isotypes of the RA-associated antibodies associated with lung parenchymal abnormalities in early, untreated RA.

\section{CONCLUSION}

In summary, we show that specific autoantibodies' patterns associate with subclinical HRCT lung abnormalities 
in patients with early, untreated RA. Our findings provide further support for an important pathogenic link between the lung and systemic autoimmunity, contributing to RA development.

\section{Author affiliations}

${ }^{1}$ Rheumatology Unit, Department of Medicine, Solna, Karolinska Institute, Karolinska University Hospital, Stockholm, Sweden

${ }^{2}$ Unité Différenciation Épithéliale et Autoimmunité Rhumatoïde, Unité Mixte de Recherche 1056, INSERM - Université de Toulouse, Toulouse, France ${ }^{3}$ Department of Radiology, Karolinska University Hospital, Stockholm, Sweden ${ }^{4}$ Division of Respiratory Medicine, Department of Medicine, Solna, Karolinska Institutet, Stockholm, Sweden

\section{Acknowledgements We thank Dr Leonid Padyukov and Dr Thomas Frisell for} statistical advice.

Contributors VJ, AH and AC designed the study. AH, GR, SN, RK, AE, MS, JG and AC helped in recruiting the participants and provided the samples. MH, MC, LN and GS helped in validating the assay. VJ, MH, KC, GR, SN, RK, AE, MS, JG and AC performed the experiments and analyses. VJ, $\mathrm{KC}$ and $\mathrm{AC}$ wrote the first draft of the manuscript. All the authors have read, revised and approved the final version of the manuscript. Funding This project has received funding from FOREUM, Foundation for Research in Rheumatology, and from the European Research Council (ERC) grant agreement CoG 2017 - 7722209_PREVENT RA, the EU/EFPIA Innovative Medicine Initiative grant agreement 777357_RTCure and the Konung Gustaf V:s och Drottning Victorias Frimurarestiftelse.

Competing interests None declared.

Patient consent for publication Not required.

Ethics approval The ethical review board of the Karolinska University Hospital, Stockholm, Sweden, approved this study and all the participants gave informed consent.

Provenance and peer review Not commissioned; externally peer reviewed.

Data availability statement Data are available upon reasonable request. All data relevant to the study are included in the article or uploaded as supplemental information.

Supplemental material This content has been supplied by the author(s). It has not been vetted by BMJ Publishing Group Limited (BMJ) and may not have been peerreviewed. Any opinions or recommendations discussed are solely those of the author(s) and are not endorsed by BMJ. BMJ disclaims all liability and responsibility arising from any reliance placed on the content. Where the content includes any translated material, BMJ does not warrant the accuracy and reliability of the translations (including but not limited to local regulations, clinical guidelines, terminology, drug names and drug dosages), and is not responsible for any error and/or omissions arising from translation and adaptation or otherwise.

Open access This is an open access article distributed in accordance with the Creative Commons Attribution Non Commercial (CC BY-NC 4.0) license, which permits others to distribute, remix, adapt, build upon this work non-commercially, and license their derivative works on different terms, provided the original work is properly cited, appropriate credit is given, any changes made indicated, and the use is non-commercial. See: http://creativecommons.org/licenses/by-nc/4.0/.

\section{ORCID iDs}

Vijay Joshua http://orcid.org/0000-0002-2606-8180

Katerina Chatzidionysiou http://orcid.org/0000-0002-2669-1247

\section{REFERENCES}

1 Nielen MM, van Schaardenburg D, Reesink HW, et al. Specific autoantibodies precede the symptoms of rheumatoid arthritis: a study of serial measurements in blood donors. Arthritis Rheum 2004;50:380-6.

2 Rantapaa-Dahlqvist S, de Jong BA, Berglin E, et al. Antibodies against cyclic citrullinated peptide and IgA rheumatoid factor predict the development of rheumatoid arthritis. Arthritis Rheum 2003;48:2741-9.

3 Catrina Al, Ytterberg AJ, Reynisdottir G, et al. Lungs, joints and immunity against citrullinated proteins in rheumatoid arthritis. Nat Rev Rheumatol 2014;10:645-53.

4 Hansson M, Mathsson L, Schlederer T, et al. Validation of a multiplex chip-based assay for the detection of autoantibodies against citrullinated peptides. Arthritis Res Ther 2012;14:R201.
5 Sokolove J, Bromberg R, Deane KD, et al. Autoantibody epitope spreading in the pre-clinical phase predicts progression to rheumatoid arthritis. PLoS One 2012;7:e35296.

6 Brink M, Hansson M, Mathsson L, et al. Multiplex analyses of antibodies against citrullinated peptides in individuals prior to development of rheumatoid arthritis. Arthritis Rheum 2013;65:899-910.

7 Arkema EV, Goldstein BL, Robinson W, et al. Anti-citrullinated peptide autoantibodies, human leukocyte antigen shared epitope and risk of future rheumatoid arthritis: a nested case-control study. Arthritis Res Ther 2013;15:R159.

8 Catrina Al, Svensson Cl, Malmstrom V, et al. Mechanisms leading from systemic autoimmunity to joint-specific disease in rheumatoid arthritis. Nat Rev Rheumatol 2017;13:79-86.

9 Klareskog L, Stolt P, Lundberg K, et al. A new model for an etiology of rheumatoid arthritis: smoking may trigger HLA-DR (shared epitope)-restricted immune reactions to autoantigens modified by citrullination. Arthritis Rheum 2006;54:38-46.

10 Padyukov L, Silva C, Stolt $P$, et al. A gene-environment interaction between smoking and shared epitope genes in HLA-DR provides a high risk of seropositive rheumatoid arthritis. Arthritis Rheum 2004;50:3085-92.

11 Makrygiannakis D, Hermansson M, Ulfgren AK, et al. Smoking increases peptidylarginine deiminase 2 enzyme expression in human lungs and increases citrullination in BAL cells. Ann Rheum Dis 2008;67:1488-92.

12 Reynisdottir G, Karimi R, Joshua V, et al. Structural changes and antibody enrichment in the lungs are early features of anti-citrullinated protein antibody-positive rheumatoid arthritis. Arthritis Rheumatol 2014;66:31-9.

13 Willis VC, Demoruelle MK, Derber LA, et al. Sputum autoantibodies in patients with established rheumatoid arthritis and subjects at risk of future clinically apparent disease. Arthritis Rheum 2013;65:2545-54.

14 Demoruelle MK, Weisman MH, Simonian PL, et al. Brief report: airways abnormalities and rheumatoid arthritis-related autoantibodies in subjects without arthritis: early injury or initiating site of autoimmunity? Arthritis Rheum 2012;1756-61.

15 Reynisdottir G, Olsen H, Joshua V, et al. Signs of immune activation and local inflammation are present in the bronchial tissue of patients with untreated early rheumatoid arthritis. Ann Rheum Dis 2016;75:1722-7.

16 Rangel-Moreno J, Hartson L, Navarro C, et al. Inducible bronchus-associated lymphoid tissue (iBALT) in patients with pulmonary complications of rheumatoid arthritis. $J$ Clin Invest 2006;116:3183-94.

17 Ytterberg AJ, Joshua V, Reynisdottir G, et al. Shared immunological targets in the lungs and joints of patients with rheumatoid arthritis: identification and validation. Ann Rheum Dis 2015;74:1772-7.

18 Arnett FC, Edworthy SM, Bloch DA, et al. The American Rheumatism Association 1987 revised criteria for the classification of rheumatoid arthritis. Arthritis Rheum 1988;31:315-24.

19 Prevoo ML, van ' $T$ Hof MA, Kuper HH, et al. Modified disease activity scores that include twenty-eight-joint counts. Development and validation in a prospective longitudinal study of patients with rheumatoid arthritis. Arthritis Rheum 1995;38:44-8.

20 Kusaka Y, Hering KG, Parker JE. International classification of HRCT for occupational and environmental respiratory diseases. Tokyo; New York, NY: Springer, 2005

21 Schittny JC. Development of the lung. Cell Tissue Res 2017;367:427-44.

22 Quanjer PH, Tammeling GJ, Cotes JE, et al. Lung volumes and forced ventilatory flows. Report working party standardization of lung function tests, European community for steel and coal. Official statement of the European Respiratory Society. Eur Respir J Suppl 1993;16:5-40.

23 Snir O, Gomez-Cabrero D, Montes A, et al. Non-HLA genes ptpn22, cdk6 and padi4 are associated with specific autoantibodies in HLA-defined subgroups of rheumatoid arthritis. Arthritis Res Ther 2014; $16: 414$.

24 Raychaudhuri S, Sandor C, Stahl EA, et al. Five amino acids in three HLA proteins explain most of the association between MHC and seropositive rheumatoid arthritis. Nat Genet 2012;44:291-6.

25 Midi H, Sarkar SK, Rana S. Collinearity diagnostics of binary logistic regression model. J Interdisciplinary Math 2010;13:253-67.

26 Kelly CA, Saravanan V, Nisar M, et al. Rheumatoid arthritis-related interstitial lung disease: associations, prognostic factors and physiological and radiological characteristics: a large multicentre UK study. Rheumatology (Oxford) 2014;53:1676-82.

27 Rocha-Munoz AD, Ponce-Guarneros M, Gamez-Nava JI, et al. Anticyclic citrullinated peptide antibodies and severity of interstitial lung disease in women with rheumatoid arthritis. $J$ Immunol Res 2015;2015:151626. 
28 Bernstein EJ, Barr RG, Austin JHM, et al. Rheumatoid arthritis-associated autoantibodies and subclinical interstitial lung disease: the multi-ethnic study of atherosclerosis. Thorax 2016;71:1082-90.

29 Svard A, Kastbom A, Sommarin Y, et al. Salivary IgA antibodies to cyclic citrullinated peptides (CCP) in rheumatoid arthritis. Immunobiology 2013;218:232-7.

30 Svard A, Skogh T, Alfredsson L, et al. Associations with smoking and shared epitope differ between IgA- and IgG-class antibodies to cyclic citrullinated peptides in early rheumatoid arthritis. Arthritis Rheumatol 2015;67:2032-7.
31 Roos K, Martinsson K, Ziegelasch M, et al. Circulating secretory IgA antibodies against cyclic citrullinated peptides in early rheumatoid arthritis associate with inflammatory activity and smoking. Arthritis Res Ther 2016;18:119.

32 Mori S, Cho I, Koga Y, et al. Comparison of pulmonary abnormalities on high-resolution computed tomography in patients with early versus longstanding rheumatoid arthritis. J Rheumatol 2008;35:1513-21.

33 Giles JT, Danoff SK, Sokolove J, et al. Association of fine specificity and repertoire expansion of anticitrullinated peptide antibodies with rheumatoid arthritis associated interstitial lung disease. Ann Rheum Dis 2014;73:1487-94 